\title{
Shear behaviour of reinforced concrete beams under impact loads by the Lumped Damage framework
}

\author{
Mateus Cardoso Oliveira, Daniel Victor da Cunha Teles, David Leonardo Nascimento de \\ Figueiredo Amorim \\ Laboratory of Mathematical Modelling in Civil Engineering, Post-graduation Programme in Civil Engineering, Department of Civil \\ Engineering, Federal University of Sergipe, São Cristóvão, Brazil \\ mateusoliver490@gmail.com, bttp://orcid.org/0000-0001-6227-8516 \\ danielvcteles@gmail.com, bttp://orcid.org/0000-0002-9206-6351 \\ david.amorim@ufs.br,http://orcid.org/0000-0002-9233-3114
}

\begin{abstract}
Impact loadings such as vehicle collisions or falling rocks on a structure could lead it to collapse and, eventually, to fatal victims. Among possible alternatives to analyse this issue, Lumped Damage Mechanics is an interesting option due to its formulation and easiness for practical application. Therefore, this paper presents a simplified Lumped Damage model to evaluate reinforced concrete structures under impact loads with shear failure mode. In the proposed approach, the damage variable is considered as an output parameter. Such damage variable takes values between zero and one, which quantifies the concrete cracking due to impact loading. The proposed formulation was applied in experiments of reinforced concrete beams under impact loads that presents shear collapse. The obtained results showed good accuracy between the proposed model and the actual structural behaviour. Moreover, a possible flowchart for practical applications is also presented. Since the model parameters are easily associated to inelastic phenomena, the proposed formulation might become accessible to engineers in practice.
\end{abstract}

KEYWORDS. Impact load; Reinforced concrete beams; Shear failure; Lumped Damage Mechanics.

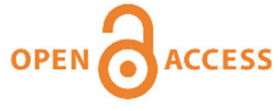

Citation: Oliveira, M.C., Teles, D.V.C., Amorim, D.L.N.F., Shear behaviour of reinforced concrete beams under impact loads by the lumped damage framework, Frattura ed Integrità Strutturale, 53 (2020) 13-25.

Received: 11.11 .2019

Accepted: 15.04 .2020

Published: 01.07.2020

Copyright: (C) 2019 This is an open access article under the terms of the CC-BY 4.0, which permits unrestricted use, distribution, and reproduction in any medium, provided the original author and source are credited.

\section{INTRODUCTION}

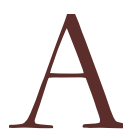
ccidents involving impact loads often occur on reinforced concrete structures. Some usual accidents are vehicles that collide on structures, explosions, rock-fall, falling of heavy objects or parts of another structure in the construction phase, and impact of ships in docks. In such cases, engineers often need a consistent and immediate result of the structural response. 
During the impact, the structural response can be obtained by Fracture Mechanics [1] or Continuous Damage Mechanics [2]. However, such theories are applied in a finite element analysis that present an excessive computational cost and depict results that difficult their use for several engineering applications, making their practical application unfeasible in many cases. On the other hand, Lumped Damage Mechanics (LDM) combines and applies fundamental concepts of Continuous Damage Mechanics and Fracture Mechanics, such as the strain equivalence hypothesis and the Griffith criterion, with the concept of plastic hinges. LDM is an interesting alternative for several civil engineering applications. This theory was initially proposed by Flórez-López [3] to analyse reinforced concrete structures under seismic loads, and the first book about LDM was published in 2015 [4]. LDM has already been used to satisfactorily analyse several structures with actual engineering applications, such as simple and reinforced concrete structures, bridges and masonry arches [5-14]. Recently, Uchoa et al. [15] proposed a LDM based methodology to estimate the loss of flexural stiffness in simple concrete beams subjected to the four-point bending experimental test.

The collapse of reinforced concrete (RC) beams subjected to impact loads can be caused by bending moment $[16,17]$ or shear force [18-22]. Li et al. [23] and Pham et al. [24] showed that the contact stiffness has limited effect in impulse and midspan displacement response. Previous studies have proposed numerical models to evaluate behaviour response of the RC beams under low impact velocity [25-29]. Fan et al. [30] proposed a finite element analysis in order to predict flexural and shear responses of RC beams and columns subjected to low impact velocity. However, due to differences in RC beams behaviour under low and high impact velocities, there are not enough studies in this theme, especially for high velocities. According to Zhao et al. [22], shear failure in RC beams has not yet been adequately understood, unlike bending failure. Kishi et al. [18] showed that RC beams that under static load fail by bending, may fail by shear when subjected to high impact loads. In order to evaluate the ability of RC beams to resist shear under impact loads, simplified analytical model have been proposed [18-21]. Nonlinear analyses using finite elements can also be applied. For instance, Zhao et al. [22] used an elastoplastic damage model with three-dimensional finite elements. This type of application results in a high computational cost and complex interpretation of the numerical results.

In the light of the foregoing, this paper presents an alternative approach based on LDM that estimates the response of RC beams subjected to shear failure due to impact loads. The proposed formulation is obtained by the thermodynamic of irreversible processes. Since the proposed formulation is quite simple, structural safety might be easily analysed with practical engineering criteria. Finally, the accuracy of the proposed LDM model is verified by comparing the obtained results with experimental responses [22].

\section{LUMPED DAMAGE MECHANICS}

\section{General overview}

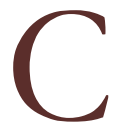

onsider a finite beam element between nodes $i$ and $j$, as the one depicted in Fig. 1a. The deformed shape of the beam element can be described by the flexure rotations $\phi_{i}$ and $\phi_{j}$ at the nodes $i$ and $j$, respectively. Both flexure rotations are set in the matrix of generalised deformations, defined as:

$$
\{\boldsymbol{\Phi}\}=\left\{\phi_{i} \quad \phi_{j}\right\}^{T}
$$

where the superscript $T$ means 'transpose of.

In order to take into account the inelastic phenomena, the finite element is now understood as an assemblage of an elasticplastic-damage Timoshenko beam with two inelastic hinges at its edges, as shown in Fig. 1b. Note that the bending inelastic effects are lumped at the hinges and the shear ones are distributed along the beam element. For RC beams, the damage variables $d_{i}$ and $d_{j}$ account for the bending concrete cracking, the plastic flexure rotations $\phi_{i}{ }^{p}$ and $\phi_{j} p$ quantify the yielding of the longitudinal reinforcement, the damage variable $d_{s}$ measures the shear concrete cracking and the plastic distortion $\gamma^{p}$ accounts for the yielding of the transversal reinforcement (Fig. 1c).

The matrix of generalised stresses $\{\mathbf{M}\}$ is defined as a set of bending moments, $M_{i}$ and $M_{j}$, which are conjugated with generalised deformations $\phi_{i}$ and $\phi_{j}$ (Fig. 1c). 


$$
\{\mathbf{M}\}=\left\{\begin{array}{ll}
M_{i} & M_{j}
\end{array}\right\}^{T}
$$

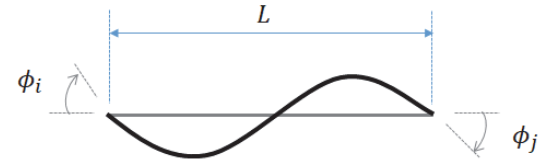

(a)

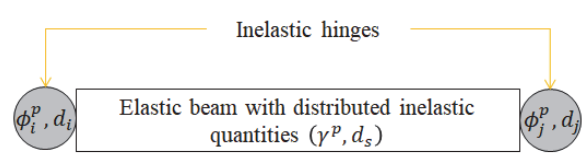

(b)

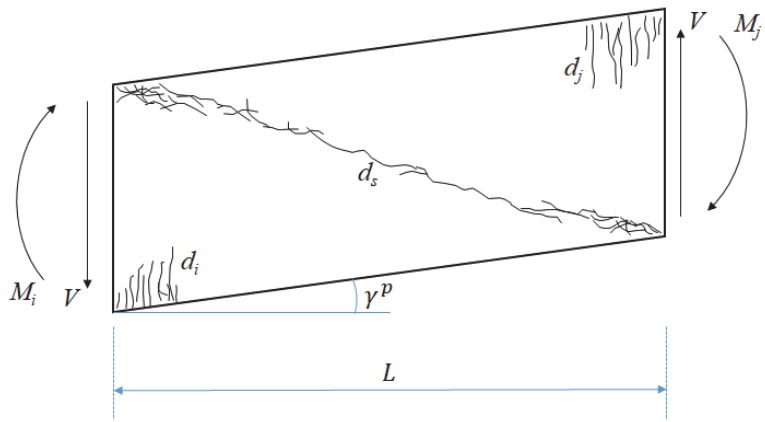

(c)

Figure 1: Lumped Damage beam: (a) deformed shape, (b) finite element and (c) inelastic variables.

According to the deformation equivalence hypothesis [4], the matrix of generalised deformations can be expressed as:

$$
\{\boldsymbol{\Phi}\}=\left\{\boldsymbol{\Phi}^{e}\right\}+\left\{\boldsymbol{\Phi}^{d}\right\}+\left\{\boldsymbol{\gamma}^{d}\right\}+\left\{\boldsymbol{\Phi}^{p}\right\}+\left\{\boldsymbol{\gamma}^{p}\right\}
$$

where $\left\{\boldsymbol{\Phi}^{e}\right\}$ is the matrix of elastic deformations, given by [4]:

$$
\left\{\boldsymbol{\Phi}^{e}\right\}=\left[\begin{array}{cc}
\frac{L}{3 E I} & -\frac{L}{6 E I} \\
-\frac{L}{6 E I} & \frac{L}{3 E I}
\end{array}\right]\{\mathbf{M}\}+\left[\begin{array}{cc}
\frac{1}{L G A} & \frac{1}{L G A} \\
\frac{1}{L G A} & \frac{1}{L G A}
\end{array}\right]\{\mathbf{M}\}
$$

being $E$ the Young's modulus, $G$ the shear modulus, $I$ the inertia moment and $A$ the cross section area; $\left\{\boldsymbol{\Phi}^{d}\right\}$ is the matrix that represents the deformation of the beam due to bending cracking in concrete by means of damage variables $\left(d_{i}\right.$ e $\left.d_{j}\right)$ in each hinge, given by [4]:

$$
\left\{\boldsymbol{\Phi}^{d}\right\}=\left[\begin{array}{cc}
\frac{L d_{i}}{3 E I\left(1-d_{i}\right)} & 0 \\
0 & \frac{L d_{j}}{3 E I\left(1-d_{j}\right)}
\end{array}\right]\{\mathbf{M}\}
$$

$\left\{\boldsymbol{\gamma}^{d}\right\}$ is the matrix that represents the beam distortion caused by diagonal shear cracks through the damage variable $d_{s}$, expressed as [4]:

$$
\left\{\gamma^{d}\right\}=\left[\begin{array}{cc}
\frac{d_{s}}{L G A\left(1-d_{s}\right)} & \frac{d_{s}}{L G A\left(1-d_{s}\right)} \\
\frac{d_{s}}{L G A\left(1-d_{s}\right)} & \frac{d_{s}}{L G A\left(1-d_{s}\right)}
\end{array}\right]\{\mathbf{M}\}
$$


$\{\Phi p\}$ is the matrix that quantifies the deformation caused by the yielding of the longitudinal reinforcement, i.e.:

$$
\left\{\boldsymbol{\Phi}^{p}\right\}=\left\{\phi_{i}^{p} \quad \phi_{j}^{p}\right\}^{T}
$$

and $\left\{\gamma^{p}\right\}$ is the matrix that represents the plastic distortion of the beam caused by the yielding of the transversal reinforcement (Fig. 1c), given by:

$$
\left\{\boldsymbol{\gamma}^{p}\right\}=\left\{\begin{array}{ll}
\gamma^{p} & \gamma^{p}
\end{array}\right\}^{T}
$$

Hence, the elastic relation is obtained by substituting (4-8) in (3):

$$
\begin{aligned}
& \left\{\boldsymbol{\Phi}-\boldsymbol{\Phi}^{p}-\boldsymbol{\gamma}^{p}\right\}=\left[\mathbf{F}_{f}\left(d_{i}, d_{j}\right)+\mathbf{F}_{s}\left(d_{s}\right)\right][\mathbf{M}\}= \\
& =\left[\begin{array}{cc}
\frac{L}{3 E I\left(1-d_{i}\right)} & -\frac{L}{6 E I} \\
-\frac{L}{6 E I} & \frac{L}{3 E I\left(1-d_{j}\right)}
\end{array}\right]\{\mathbf{M}\}+\left[\begin{array}{cc}
\frac{1}{L G A\left(1-d_{s}\right)} & \frac{1}{L G A\left(1-d_{s}\right)} \\
\frac{1}{L G A\left(1-d_{s}\right)} & \frac{1}{L G A\left(1-d_{s}\right)}
\end{array}\right]\{\mathbf{M}\}
\end{aligned}
$$

where $\left[\mathbf{F}_{f}\left(d_{i}, d_{j}\right)\right]$ and $\left[\mathbf{F}_{s}\left(d_{s}\right)\right]$ are the flexibility matrices due flexural and shear cracking, respectively.

\section{Thermodynamic approach}

Considering a beam element with a certain level of flexure and shear damage as well as plastic rotations and distortion, the total thermodynamic potential is given by the Helmholtz's free specific energy [34, 35]:

$$
\chi=\frac{1}{2}\left\{\boldsymbol{\Phi}-\boldsymbol{\Phi}^{p}-\boldsymbol{\gamma}^{p}\right\}^{T}[\mathbf{E}(\mathbf{D})]\left\{\boldsymbol{\Phi}-\boldsymbol{\Phi}^{p}-\boldsymbol{\gamma}^{p}\right\}
$$

being $\chi$ the total thermodynamic potential and $[\mathbf{E}(\mathbf{D})]$ the stiffness matrix of the damaged element, given by:

$$
\mathbf{E}(\mathbf{D})]=\left[\mathbf{F}_{f}\left(d_{i}, d_{j}\right)+\mathbf{F}_{s}\left(d_{s}\right)\right]^{-1}
$$

where $(\mathbf{D})=\left(d_{i}, d_{j}, d_{s}\right)$ is the set of the damage variables.

For a proper definition, the model must be thermodynamically admissible. This condition is achieved through ClausiusDuhem inequality, which is also called as non-negative dissipation. Thus, considering that the process is isothermal, such inequality is expressed as:

$$
\{\mathbf{M}\}^{T}\{\dot{\boldsymbol{\Phi}}\}-\dot{\chi} \geq 0
$$

where the first term is the variation of the internal energy involved in the process and the second one is the variation of the thermodynamic potential.

Assuming that the total thermodynamic potential can be linearized around the current values of the state variables, then:

$$
\dot{\chi}=\left\{\frac{\partial \chi}{\partial\{\boldsymbol{\Phi}\}}\right\}^{T}\{\dot{\boldsymbol{\Phi}}\}+\left\{\frac{\partial \chi}{\partial\left\{\boldsymbol{\Phi}^{p}\right\}}\right\}^{T}\left\{\dot{\boldsymbol{\Phi}}^{p}\right\}+\left\{\frac{\partial \chi}{\partial\left\{\boldsymbol{\gamma}^{p}\right\}}\right\}^{T}\left\{\dot{\boldsymbol{\gamma}}^{p}\right\}+\left\{\frac{\partial \chi}{\partial\{\mathbf{D}\}}\right\}^{T}\{\dot{\mathbf{D}}\}
$$

Therefore, the Clausius-Duhem inequality is rewritten as: 


$$
\left(\{\mathbf{M}\}^{T}-\left\{\frac{\partial \chi}{\partial\{\boldsymbol{\Phi}\}}\right\}^{T}\right)\{\dot{\boldsymbol{\Phi}}\}-\left\{\frac{\partial \chi}{\partial\left\{\boldsymbol{\Phi}^{p}\right\}}\right\}^{T}\left\{\dot{\boldsymbol{\Phi}}^{p}\right\}-\left\{\frac{\partial \chi}{\partial\left\{\boldsymbol{\gamma}^{p}\right\}}\right\}^{T}\left\{\dot{\boldsymbol{\gamma}}^{p}\right\}-\left\{\frac{\partial \chi}{\partial\{\mathbf{D}\}}\right\}^{T}\{\dot{\mathbf{D}}\} \geq 0
$$

Eqn. (14) must be obeyed in any thermodynamic process, including one that is fully reversible, where the inelastic effects are null. This can be observed since the derivation of the total thermodynamic potential in relation to the total generalised deformations results in the generalised stress matrix, according to the following expression:

$$
\left\{\frac{\partial \chi}{\partial\{\boldsymbol{\Phi}\}}\right\}=[\mathbf{E}(\mathbf{D})]\left[\boldsymbol{\Phi}-\boldsymbol{\Phi}^{p}-\boldsymbol{\gamma}^{p}\right\}=\{\mathbf{M}\}
$$

The other differential relations of thermodynamic potential in relation to state variables are given by the following expressions:

$$
\begin{aligned}
& \left\{\frac{\partial \chi}{\partial\left\{\mathbf{\Phi}^{p}\right\}}\right\}=-[\mathbf{E}(\mathbf{D})]\left\{\mathbf{\Phi}-\mathbf{\Phi}^{p}-\boldsymbol{\gamma}^{p}\right\}=-\{\mathbf{M}\} \\
& \left\{\frac{\partial \chi}{\partial\left\{\boldsymbol{\gamma}^{p}\right\}}\right\}=-[\mathbf{E}(\mathbf{D})]\left\{\mathbf{\Phi}-\mathbf{\Phi}^{p}-\boldsymbol{\gamma}^{p}\right\}=-\{\mathbf{M}\} \\
& \left\{\frac{\partial \chi}{\partial\{\mathbf{D}\}}\right\}=\left\{\begin{array}{l}
-\frac{L M_{i}^{2}}{6 E I\left(1-d_{i}\right)^{2}} \\
-\frac{L M_{j}^{2}}{6 E I\left(1-d_{j}\right)^{2}} \\
-\frac{\left(M_{i}+M_{j}\right)^{2}}{2 L G A\left(1-d_{s}\right)^{2}}
\end{array}\right\}=\left\{\begin{array}{l}
-Y_{i} \\
-Y_{j} \\
-Y_{s}
\end{array}\right\}=\{\mathbf{Y}\}
\end{aligned}
$$

It is observed that $\{\mathbf{M}\},-\{\mathbf{M}\},-\{\mathbf{M}\}$ and $\{\mathbf{Y}\}$ are the thermodynamics variables associated with $\{\boldsymbol{\Phi}\},\left\{\Phi^{p}\right\},\left\{\boldsymbol{\gamma}^{p}\right\}$ and $\{\mathbf{D}\}$, respectively, being $Y_{i}$ and $Y_{j}$ the damage driving moments of the hinges $i$ and $j$, and $Y_{s}$ the damage driving moment of the shear cracking along the beam [4]. Therefore, by substituting the expressions (15-18) in the inequality (14) and assuming the predominance of shear effects, then:

$$
\{\mathbf{M}\}^{T}\left\{\dot{\boldsymbol{\gamma}}^{p}\right\}+Y_{s} \dot{d}_{s} \geq 0
$$

The inequality (19) must be obeyed throughout the structural analysis. Therefore, the positivity of each term must be ensured separately, since both inelastic phenomena (plastic deformations and damage) can occur non-simultaneously (considering any application, not only for RC beams). In the first term of (19) it is noted that the internal stress present in the matrix $\{\mathbf{M}\}$ always have the same signs of the generalised plastic distortion rate, therefore, the positivity of the first term is verified. Since the physical and geometric properties of the structural element under analysis, as well as the damage variable, are always positive, then the positivity of the second term is achieved.

\section{PROPOSED MODELLING OF IMPACT PROBLEMS}

$\mathrm{I}$ $\mathrm{n}$ order to analyse the nonlinear response of simply supported beams under impact loads, Fujikake et al. [17] performed experiments in which a known mass body (hammer) is released from four different heights. With these experiments, an analytical model based on the energy balance of a two-degree-of-freedom mass-spring-damping system was 
presented with the purpose of quantify the behaviour of RC beams under impact loads. Thus, the energy dissipated $\left(E_{p}\right)$ during the impact is given by [17]:

$$
E_{p}=\int P(w) d w=\frac{m_{2} v^{2}}{2}-\frac{m_{1} m_{2}}{2\left(m_{1}+m_{2}\right)} v^{2}+\left(m_{1}+m_{2}\right) g w_{\max }
$$

being $m_{1}$ and $m_{2}$ the beam and hammer masses respectively, $g$ the acceleration of gravity, $w_{\max }$ the maximum displacement (mid-span), and $v$ the impact velocity, given by:

$$
v=\sqrt{2 g h}
$$

where $b$ is the drop height.

It is worthy noted that the analytical Eqn. (20), presented by Fujikake et al. [17], has been successfully applied on shear impact problems in the technical literature [18-21]. Therewith, by equalling both energy dissipation equations, i.e. (19) and (20), for a simply supported beam as the one depicted in Fig. 2 and assuming, for the sake of simplicity, that shear damage and plastic distortion after impact are characterised by their final values $\left(d_{s}\right.$ and $\left.\gamma^{p}\right)$, then:

$$
\frac{m_{2} v^{2}}{2}-\frac{m_{1} m_{2}}{2\left(m_{1}+m_{2}\right)} v^{2}+\left(m_{1}+m_{2}\right) g w_{\max }=M_{j} \gamma^{p}+\frac{M_{j}^{2}}{2 L G A\left(1-d_{s}\right)^{2}} d_{s}
$$

being the bending moment $M_{j}$ calculated with the mean impact force $P_{m}$ (Fig. 3):

$$
P_{m}=\frac{I_{p}}{T_{d}} \quad \therefore I_{p}=\int_{0}^{T_{d}} P(t) d t
$$

where $I_{p}$ is the impulse and $T_{d}$ is the impact duration.

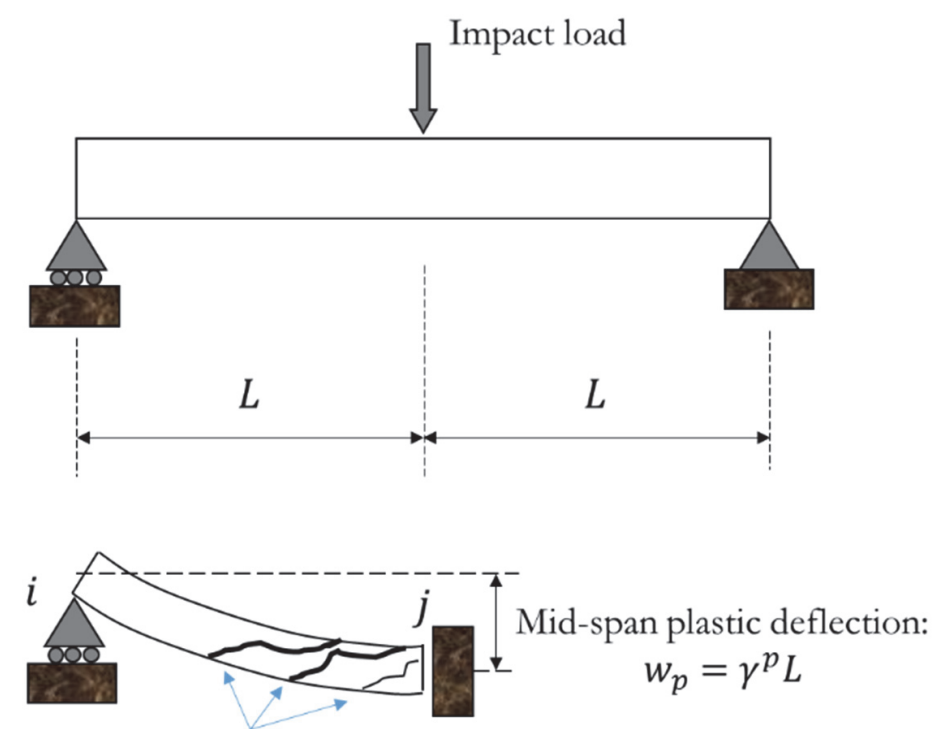

Shear cracks

Figure 2: Simply supported beam under impact load and its mathematical model in the aftermath. 


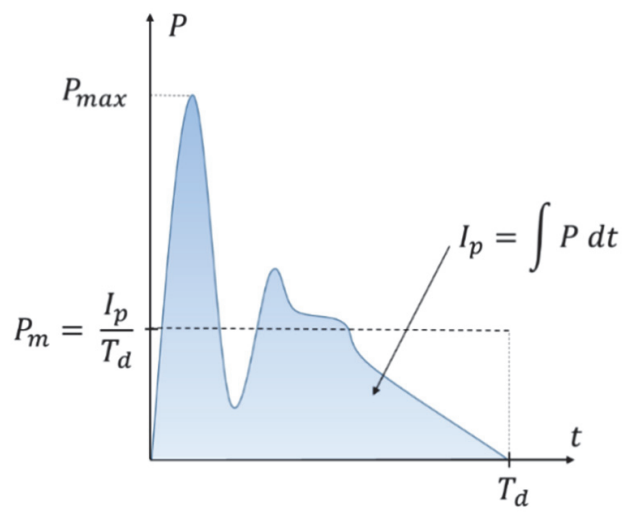

Figure 3: Force-time graph for impact loads.

\section{RESULTS AND DISCUSSION}

$\mathrm{E}$ xperiments performed by Zhao et al. [22] and Bhatti et al. [37] were used in order to analyse the proposed shear impact model.

\section{Zhao et al. [22]}

The beams present $3 \mathrm{~m}$ span $(2 \mathrm{~L})$, longitudinal reinforcement composed of four bars with $20 \mathrm{~mm}$ in the tension side and two bars with $16 \mathrm{~mm}$ in the compression side, with yield stress of $495.5 \mathrm{MPa}$ and ultimate tension of 620.2MPa. The stirrups consisted of $6 \mathrm{~mm}$ bars spaced by $30 \mathrm{~cm}$, with yield stress $344.7 \mathrm{MPa}$ and ultimate tension of $550.4 \mathrm{MPa}$ [22]. Other properties of the beams are presented in Tab. 1, as well as some dynamic response values.

\begin{tabular}{cccc}
\hline $\begin{array}{c}\text { Beam - impact weight } \\
(\mathrm{kg}) \text { - drop height }(\mathrm{m})\end{array}$ & Cross section $(\mathrm{cm})$ & $\begin{array}{c}\text { Compressive strength } \\
\text { of concrete }(\mathrm{MPa})\end{array}$ & $\begin{array}{c}\text { Mean impact force } \\
(\mathrm{kN})\end{array}$ \\
Beam C-1700-4.60 & & 32.14 & 205.22 \\
Beam C-1300-5.56 & $20 \times 50$ & 30.25 & 296.88 \\
Beam C-868-7.14 & & 26.26 & 286.71 \\
\hline
\end{tabular}

Table 1: Properties of the analysed beams.

Therefore, for each beam, the damage variable $\left(d_{s}\right)$ and the plastic distortion are obtained from Eqn. (9) and (22). This calculation process was performed to evaluate the applicability of the proposed formulation. The damage and the plastic distortion calculated on each beam is shown in Tab. 2. Fig. 3 shows a scheme with the crack pattern after impact.

The obtained damage values are high, meaning that a severe cracking level in the three beams, which is consistent with the experimentally observed cracking patterns (Fig. 4). Furthermore, by knowing the value of the plastic distortion $\left(\gamma^{p}\right)$, it is possible to determine the plastic displacement of the beam (Fig. 2):

$$
w_{p}=\gamma^{p} L
$$

In order to illustrate the proposed approach, the solution of Beam C-1700-4.60 [22] is described as follows. Firstly, Eqn. (9) must be rewritten to agree with the mathematical model of the beam (Fig. 2). Therewith, it is assumed that the inelastic effects due to bending moment are negligible. Then, the constitutive relation for a simply supported beam is given as:

$$
\left\{\boldsymbol{\Phi}-\boldsymbol{\gamma}^{p}\right\}=\left[\mathbf{F}_{f}+\mathbf{F}_{s}\left(d_{s}\right)\right]\{\mathbf{M}\}
$$


which leads to:

$$
\phi_{j}=\gamma^{p}+\frac{L}{3 E I} M_{j}+\frac{1}{L G A\left(1-d_{s}\right)} M_{j}
$$

\begin{tabular}{|c|c|c|c|c|}
\hline $\begin{array}{l}\text { Beam - impact weight } \\
(\mathrm{kg}) \text { - fall height }(\mathrm{m})\end{array}$ & Damage $\left(d_{s}\right)$ & Plastic distortion $\left(\gamma^{p}\right)$ & $\begin{array}{l}\text { Estimated plastic } \\
\text { displacement }(\mathrm{cm})\end{array}$ & $\begin{array}{l}\text { Experimental plastic } \\
\text { displacement }(\mathrm{cm}) \text { [22] }\end{array}$ \\
\hline Beam C-1700-4.60 & 0.9681 & 0.0750729 & 11.3 & Not Available \\
\hline Beam C-1300-5.56 & 0.9603 & 0.0402814 & 6.0 & $\cong 5.2$ \\
\hline Beam C-868-7.14 & 0.9601 & 0.0404670 & 6.1 & $\cong 5.0$ \\
\hline
\end{tabular}

Table 2: Damage and plastic distortion results for the analysed beams.

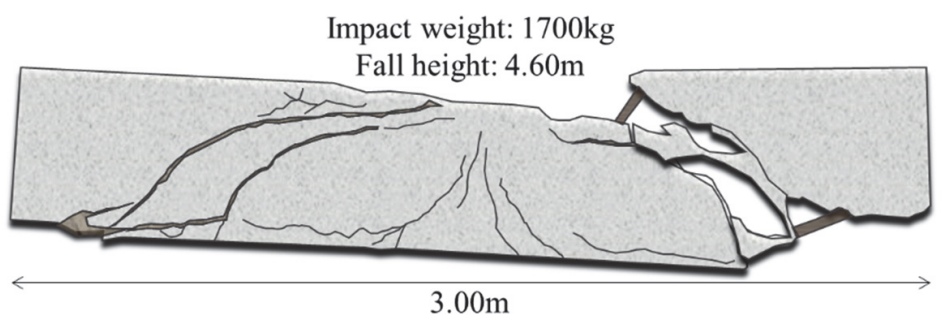

Impact weight: $1300 \mathrm{~kg}$

Fall height: $5.56 \mathrm{~m}$

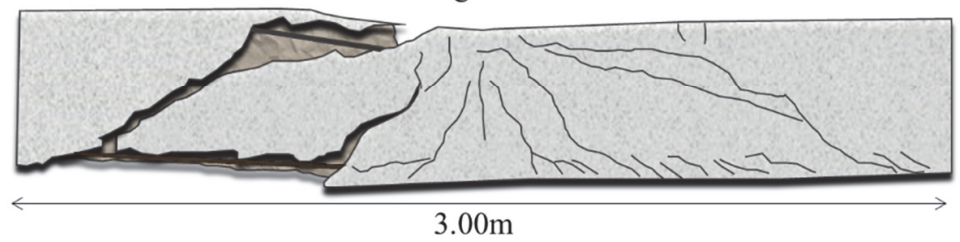

Impact weight: $868 \mathrm{~kg}$

Fall height: $7.14 \mathrm{~m}$

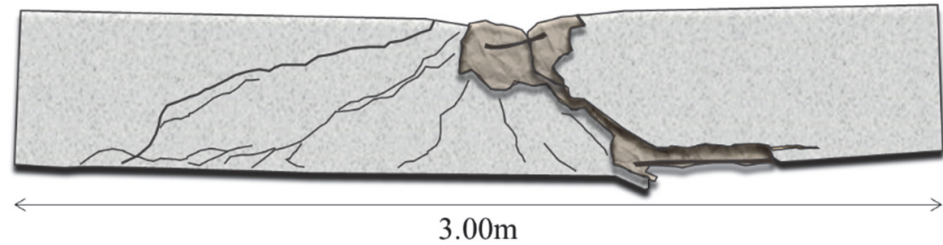

Figure 4: Beam cracking patterns after impact. (Source: adapted from Zhao et al. [22]).

Since Zhao et al. [22] presented the maximum displacement $\left(w_{\max }\right)$ of the beam, Eqn. (26) can be rewritten as:

$$
\phi_{j}=\frac{w_{\max }}{L}=\gamma^{p}+\frac{L}{3 E I} M_{j}+\frac{1}{L G A\left(1-d_{s}\right)} M_{j}
$$

Note that Eqn. (27) is a simple rearrangement of Eqn. (9) according to the analysed problem. The Young's modulus can be estimated by any design code regulation. In this paper, the Brazilian code [36] was used i.e. 


$$
E=5600 \sqrt{f_{c k}}
$$

being $f_{c k}$ the compressive strength of concrete, given in MPa.

For Beam C-1700-4.60 [22], Eqns. (27) and (22) give, respectively, the following relations (units in N and m):

$$
\begin{aligned}
& 0.07866666667=\gamma^{p}+0.001163539185+\frac{0.00007756927894}{\left(1-d_{s}\right)} \\
& 17227.43033=153914.9250 \gamma^{p}+\frac{5.969534875 d_{s}}{\left(1-d_{s}\right)^{2}}
\end{aligned}
$$

Then, by solving this nonlinear system (29-30) the shear damage $\left(d_{s}\right)$ and plastic distortion $\left(\gamma^{p}\right)$ are, respectively, 0.9681 and 0.0750729 . Finally, by using Eqn. (24) the plastic displacement $\left(w_{p}\right)$ is estimated in $11.3 \mathrm{~cm}$.

Bhatti et al. [37]

The beams presented span of $2.0 \mathrm{~m}$ and cross section with $20 \mathrm{~cm}$ of basis and $40 \mathrm{~cm}$ of height. The concrete compressive strength is $41.2 \mathrm{MPa}$ and its Young's Modulus is $25.7 \mathrm{GPa}$. All beams casted by Bhatti et al. [37] present two rebars of $35 \mathrm{~mm}$ as longitudinal reinforcement at both sides and two types of transversal reinforcements: $6 \mathrm{~mm} @ 15.0 \mathrm{~cm}$ (type A) and $6 \mathrm{~mm} @ 7.5 \mathrm{~cm}$ (type B). Both longitudinal and transversal reinforcements present yield stress and Young's modulus of $373 \mathrm{MPa}$ and $206 \mathrm{GPa}$, respectively. The impact velocity and the mean impact force on each beam is given in Tab. 3.

\begin{tabular}{cc}
\hline Beam - impact velocity $(\mathrm{m} / \mathrm{s})$ & Mean impact force $(\mathrm{kN})$ \\
A-4.6 & 397.35 \\
A-6.5 & 463.05 \\
A-8.4 & 635.66 \\
B-4.6 & 419.47 \\
B-7.4 & 509.01 \\
B-9.3 & 614.62 \\
\hline
\end{tabular}

Table 3: Properties of the analysed beams.

\begin{tabular}{|c|c|c|c|c|}
\hline $\begin{array}{c}\text { Beam - impact velocity } \\
(\mathrm{m} / \mathrm{s})\end{array}$ & Damage $\left(d_{s}\right)$ & Plastic distortion $\left(\gamma^{p}\right)$ & $\begin{array}{l}\text { Estimated plastic } \\
\text { displacement }(\mathrm{cm})\end{array}$ & $\begin{array}{l}\text { Experimental plastic } \\
\text { displacement }(\mathrm{cm})\end{array}$ \\
\hline A-4.6 & 0.9446 & 0.0066656 & 0.667 & $\cong 0.362$ \\
\hline A-6.5 & 0.9505 & 0.0107417 & 1.074 & $\cong 0.590$ \\
\hline A-8.4 & 0.9516 & 0.0184035 & 1.840 & $\cong 0.944$ \\
\hline B-4.6 & 0.9327 & 0.0070843 & 0.708 & $\cong 0.203$ \\
\hline B-7.4 & 0.9469 & 0.0143020 & 1.430 & $\cong 0.663$ \\
\hline B-9.3 & 0.9579 & 0.0201287 & 2.013 & $\cong 1.235$ \\
\hline
\end{tabular}

Therefore, damage and plastic distortion were obtained by applying the same procedure previously illustrated (Tab. 4). Fig. 5 shows cracking pattern presented in the beams after impact.

Table 4: Damage and plastic distortion results for the analysed beams. 
A 4.6

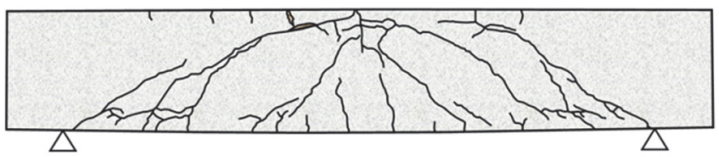

A 6.5

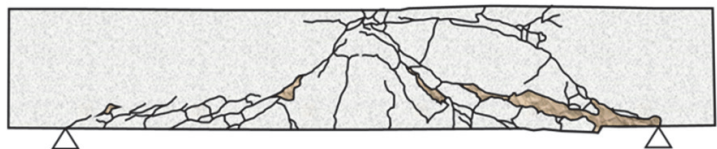

A 8.4

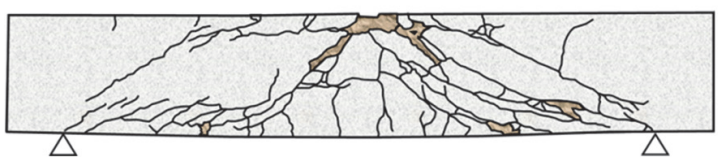

B 4.6

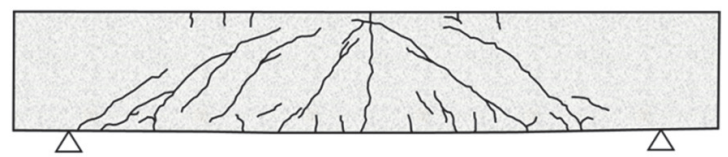

B 7.4

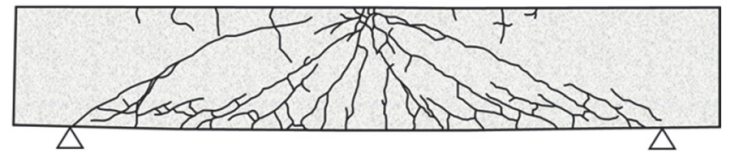

B 9.3

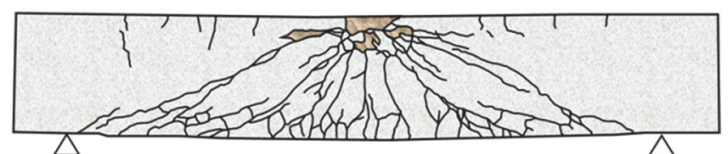

Figure 5: Beam cracking patterns after impact. (Source: adapted from Bhatti et al. [37]).

Note that the calculated plastic displacements are quite close to the experimental ones. The absolute difference between the estimated and experimental responses varies from $0.305 \mathrm{~cm}$ to $0.846 \mathrm{~cm}$, approximately. Note that in all cases the estimated response is greater than the experimental one. Therefore, the proposed procedure can estimate the actual structural behaviour analytically. Since the proposed formulation can be applied to real problems quite easily, a sequence of actions is proposed based on the flowchart shown in Fig. 6. Thus, during accidents involving impact load on reinforced concrete structures, the field engineer can obtain the necessary parameters for the model damage calculation, which are: data of the structure characteristics, obtained in the design; data of the impact nature that can be measured with an analysis of where the accident occurred and the application of basic concepts of Physics. Thus, from the level of permanent deformation of the structure, it is possible to calculate the plastic distortion. Then the damage $\left(d_{s}\right)$ and maximum displacement $\left(w_{\max }\right)$ values are calculated based on Eqn. (22). Finally, as observed in the experiments of Zhao et. al. [22], the damage variable indicates how severe the impact load was and, then, could be used to create practical engineering criteria.

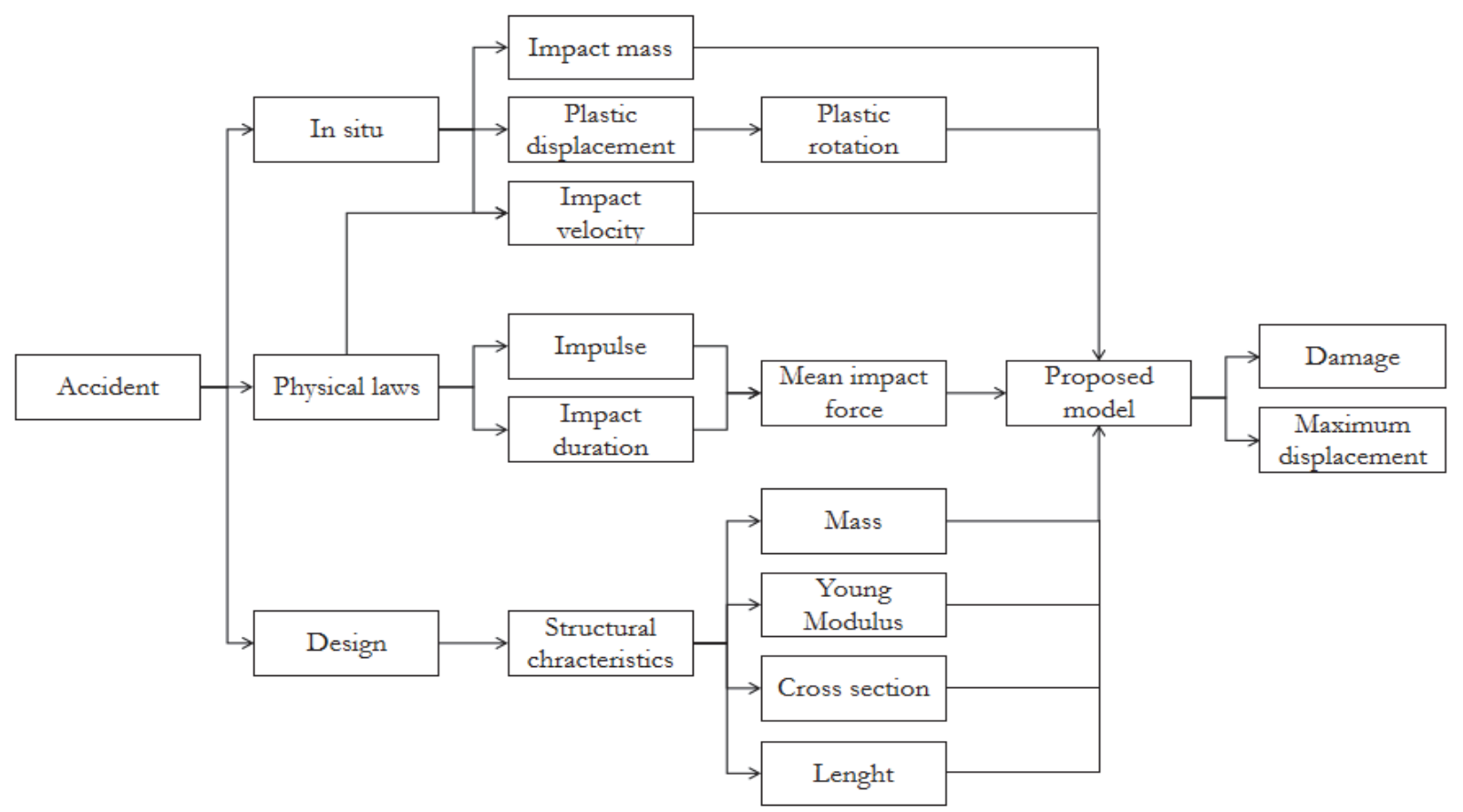

Figure 6: Demonstrative flowchart of the structural accident assessment procedure. 


\section{CONCLUSIONS}

$\mathrm{T}$ he proposed shear impact model was able to obtain damage, plastic distortion and plastic displacement values for each beam tested by Zhao et al. [22] and Bhatti et al. [37]. This damage variable is associated with the cracking level of the beam due to the shear effect. Analogously, the calculated plastic distortion is associated with the stirrup yielding. Note that the damage and plastic displacement values calculated with the proposed formulation are in agreement with the experimental observations of Zhao et al. [22].

A possibility for practical applications is represented by a flowchart (Fig. 6) that describes the procedure for obtaining the necessary data and then indicates their application in the proposed model, obtaining the damage values and maximum displacement of the structure. By means of the damage value, it is possible to objectively evaluate cracking level of the structural element and then determine its type of rehabilitation. Therefore, further experiments are needed to corroborate and validate the accuracy of the proposed formulation.

Notwithstanding, it is expected that with a larger experimental campaign it will be possible to adjust equations that describe the concrete crack resistance and reinforcement yielding, similar to that performed by Teles et. al. [29]. Additionally, with more results it is possible to relate damage ranges with repair levels, similar to the ones proposed by Flórez-López et al. [4] for static loadings.

\section{ACKNOWLEDGEMENTS}

$\mathrm{T}$

he authors thank the Laboratory of Mathematical Modelling in Civil Engineering of the Post-graduation Programme in Civil Engineering of the Federal University of Sergipe - LAMEC/PROEC/UFS for the physical space during the development of this work. The second author thanks COPES/POSGRAP/UFS for their financial support.

\section{REFERENCES}

[1] Broek, D. (1984). Elementary engineering fracture mechanics, Dordrecht, Martinus Nijhoff Publishers.

[2] Lemaitre, J., Chaboche, J.L. (1985). Mécaniques des matériaux solides, 1. ed., Paris, Dunod.

[3] Flórez-López, J. (1991). Modelos de daño concentrado para la simulación del colapso de pórticos planos, Rev. Int. Metod. Numer., 9(2), pp. 123-139.

[4] Flórez-López, J., Marante, M.E., Picón, R. (2015). Fracture and damage mechanics for structural engineering of frames: state-of-the-art industrial applications, Hershey, IGI Global. DOI: 10.4018/978-1-4666-6379-4.

[5] Cipollina, A., López-Inojosa, A., Flórez-López, J. (1995). A simplified damage mechanics approach to nonlinear analysis of frames. Comput. Struct., 54(6), pp. 1113-1126. DOI: 10.1016/0045-7949(94)00394-I.

[6] Liu, Y.-B., Liu, J.-B. (2004). A damage beam element model for nonlinear analysis of reinforced concrete member, Earthq. Eng. Eng. Vib., 24(2), pp. 95-100.

[7] Araujo, F., Proença, S.P.B. (2008). Application of a lumped dissipation model to reinforced concrete structures with the consideration of residual strains and cycles of hysteresis, J. Mech. Mater. Struct., 3(5), pp. 1011-1031. DOI: $10.2140 /$ jomms.2008.3.1011.

[8] Faleiro, J., Oller, S., Barbat, A.H. (2010). Plastic-damage analysis of reinforced concrete frames, Eng. Computation., 27(1), pp. 57-83. DOI: 10.1108/02644401011008522.

[9] Alva, G. M. S., El Debs, A. L. H. C. (2010). Application of lumped dissipation model in nonlinear analysis of reinforced concrete structures, Eng. Struct., 132(4), pp. 974-981. DOI: 10.1016/j.engstruct.2009.12.024.

[10] Toi, Y., Hasegawa, K.H. (2011). Element-size independent, elasto-plastic damage analysis of framed structures using the adaptively shifted integration technique, Comput. Struct., 89(23-24), pp. 2162-2168.

DOI: 10.1016/j.compstruc.2011.09.002.

[11] Perdomo, M.E., Picón, R., Marante, M.E., Hild, F., Roux, S., Flórez-López, J. (2013). Experimental analysis and mathematical modeling of fracture in RC elements with any aspect ratio, Eng. Struct., 46, pp. 407-416, DOI: 10.1016/j.engstruct.2012.07.005. 
[12] Santoro, M.G., Kunnath, S.K. (2013). Damage-based RC beam element for nonlinear structural analysis, Eng. Struct., 49, pp. 733-742. DOI: 10.1016/j.engstruct.2012.12.026.

[13] Amorim, D. L. N. F., Proença, S. P. B., Flórez-López, J. (2013). A model of fracture in reinforced concrete arches based on Lumped Damage Mechanics, Int. J. Solids Struct., 50(24), pp. 4070-4079. DOI: 10.1016/j.ijsolstr.2013.08.012.

[14] Amorim, D. L. N. F., Proença, S. P. B., Flórez-López, J. (2014). Simplified modeling of cracking in concrete: application in tunnel linings, Eng. Struct., 70, pp. 23-35. DOI: 10.1016/j.engstruct.2014.03.031.

[15] Uchoa, B.C.L., Amorim, D.L.N.F., Assis, W.S. (2018). Aplicação da teoria do dano concentrado para estimativa da rigidez à flexão em vigas de concreto simples. Proceedings of the 1 st Iberic Conference on Theoretical and Experimental Mechanics and Materials / 11th National Congress on Experimental Mechanics, 729-38, Porto, Portugal.

[16] Hughes, G., Beeby, A.W. (1982). Investigation of the effect of impact loading on concrete beams, Struct. Eng., 60, pp. 45-52.

[17] Fujikake, K., Li, B., Soeun, S. (2009). Impact Response of Reinforced Concrete Beam and Its Analytical Evaluation, J. Struct. Eng-ASCE, 135(August 2009), pp. 938-50. DOI: 10.1061/(ASCE)ST.1943-541X.0000039.

[18] Kishi, N., Mikami, H., Matsuoka, K., Ando, T. (2002). Impact behavior of shear-failure-type RC beams without shear rebar, Int. J. Impact Eng., 27(9), pp. 955-968. DOI: 10.1016/S0734-743X(01)00149-X.

[19] Saatci, S., Vecchio, F. J. (2009). Effects of shear mechanisms on impact behavior of reinforced concrete beams, ACI Struct. J., 106(1), pp. 78-86. DOI: 10.14359/56286.

[20] Cotsovos, D. M. (2010). A simplified approach for assessing the load carrying capacity of reinforced concrete beams under concentrated load applied at high rates, Int. J. Impact Eng., 37(8), pp. 907-917.

DOI: 10.1016/j.ijimpeng.2010.01.005.

[21] Yi, W.-J., Zhao, D.-B., Kunnath, S.K. (2016). Simplified Approach for Assessing Shear Resistance of Reinforced Concrete Beams under Impact Loads, ACI Struct. J., 113(4), pp. 747-756. DOI: 10.14359/51688617.

[22] Zhao, D., Yi, W., Kunnath, S.K., Asce, F. (2017). Shear Mechanisms in Reinforced Concrete Beams under Impact Loading, J. Sruct. Eng., 143(9), pp. 1-13, DOI: 10.1061/(ASCE)ST.1943-541X.0001818.

[23] Li, H., Chen, W., \& Hao, H. (2018). Influence of drop weight geometry and interlayer on impact behavior of RC beams, Int. J. Impact Eng., 131, pp. 222-237, DOI: 10.1016/j.ijimpeng.2019.04.028.

[24] Pham, T. M., Hao, Y., \& Hao, H. (2018). Sensitivity of impact behaviour of RC beams to contact stiffness, Int. J. Impact Eng., 112, pp. 155-164, DOI: 10.1016/j.ijimpeng.2017.09.015.

[25] Wongmatar, P., Hansapinyo, C., Vimonsatit, V., \& Chen, W. (2018), Recommendations for designing reinforced concrete beams against low velocity impact loads, Int. J. Struct. Stab. Dy., 18(09), pp. 1850104-1-1850104-21, DOI: $10.1142 /$ S0219455418501043.

[26] Adhikary, S. D., Li, B., \& Fujikake, K. (2015). Low velocity impact response of reinforced concrete beams: experimental and numerical investigation, Int. J. Prot. Struct., 6(1), pp. 81-111, DOI: 10.1260/2041-4196.6.1.81.

[27] Adhikary, S. D., Li, B., \& Fujikake, K. (2016). State-of-the-art review on low-velocity impact response of reinforced concrete beams, Mag. Concrete Res., 68(14), pp. 701-723, DOI: 10.1680/jmacr.15.00084.

[28] Das Adhikary, S., \& Li, B. (2018). Simplified Analytical Models to Predict Low-Velocity Impact Response of RC Beams, Pract. Period. Struct. Des. Construct., 23(2), pp. 04018002-1-04018002-10, DOI: $10.1061 /$ (ASCE)SC.1943-5576.0000357.

[29] Teles, D. V. C., Oliveira, M. C., \& Amorim, D. L. N. F. (2020). A simplified lumped damage model for reinforced concrete beams under impact loads, Eng. Struct., 205(110070), pp. 1-10, DOI: 10.1016/j.engstruct.2019.110070.

[30] Fan, W., Liu, B., Huang, X., \& Sun, Y. (2019). Efficient modeling of flexural and shear behaviors in reinforced concrete beams and columns subjected to low-velocity impact loading, Eng. Struct., 195, pp. 22-50, DOI: $10.1016 /$ j.engstruct.2019.05.082.

[31] Saatci, S., Vecchio, F. J. (2009). Effects of shear mechanisms on impact behavior of reinforced concrete beams, ACI Struct. J., 106(1), pp. 78-86. DOI: 10.14359/56286.

[32] Cotsovos, D. M. (2010). A simplified approach for assessing the load carrying capacity of reinforced concrete beams under concentrated load applied at high rates, Int. J. Impact Eng., 37(8), pp. 907-917. DOI: 10.1016/j.ijimpeng.2010.01.005.

[33] Yi, W.-J., Zhao, D.-B., Kunnath, S.K. (2016). Simplified Approach for Assessing Shear Resistance of Reinforced Concrete Beams under Impact Loads, ACI Struct. J., 113(4), DOI: 10.14359/51688617. 
[34] Lemaitre, J., Desmorat, R. (2005). Engineering Damage Mechanics, Berlin, Springer-Verlag.

[35] Ragueneau, F., La Borderie, C., Mazars, J. (2000). Damage model for concrete-like materials coupling cracking and friction, contribution towards structural damping: first uniaxial applications, Mech. Cohes.-Frict. Mat., 5(8), pp. 607625. DOI: 10.1002/1099-1484(200011)5:8<607::AID-CFM108>3.0.CO;2-K.

[36] Associação Brasileira de Normas Técnicas. NBR 6118: Projeto de estruturas de concreto — Procedimento. Rio de Janeiro, pp. 238. 2014.

[37] Bhatti, A. Q., Kishi, N., Mikami, H., Ando, T. (2009). Elasto-plastic impact response analysis of shear-failure-type RC beams with shear rebars. Mater. Design., 30(3), pp. 502-510. DOI: 10.1016/j.matdes.2008.05.068. 